\title{
Polymerization of Methyl Methacrylate with $\mathrm{N}$-Benzyl Quinolinium Chloride- $\mathrm{Na}_{2} \mathrm{~S}_{2} \mathrm{O}_{4}-\mathrm{CCl}_{4}$ in Aqueous-Organic Two-Phase System
}

\author{
Shozo Shimada, Yasuhiko Obata, ${ }^{*}$ Katsuhiko Nakagawa, ${ }^{* *}$ \\ and Kenzo TABUCHI** \\ SUNFCO, Ltd., 5-5, Nishitenma, 4-chome, Kita-ku, Osaka 530, Japan \\ * Rengo Ltd. Fukui Devision, 96-11, Asahi, Kanatsu-cho, Sakai-gun, \\ Fukui 919-06, Japan \\ ** Department of Industrial Chemistry, Niihama National College of Technology, \\ 7-1 Yagumo-cho, Niihama 792, Japan
}

(Received August 12, 1992)

\begin{abstract}
The polymerization of methyl methacrylate with $N$-benzyl quinolinium chloride $\left(\mathrm{BQ}^{+} \mathrm{Cl}^{-}\right)-\mathrm{Na}_{2} \mathrm{~S}_{2} \mathrm{O}_{4}-\mathrm{CCl}_{4}$ initiator system was investigated in aqueous-organic two-phase system. The initial rate of polymerization $\left(R_{\mathrm{p}}\right)$ was proportional to the square root of fed quantity of initator components, $\mathrm{BQ}^{+} \mathrm{Cl}^{-}, \mathrm{Na}_{2} \mathrm{~S}_{2} \mathrm{O}_{4}$, and $\mathrm{CCl}_{4}$, respectively. $R_{\mathrm{p}}$ was also affected by the rate of stirring. A cyclic phase-transfer initiation mechanism is proposed to account for the experimental data.
\end{abstract}

KEY WORDS Polymerization / Methyl Methacrylate / $N$-Benzyl Quinolinium Chloride / Sodium Dithionite / Carbon Tetrachloride /

In the previous paper, ${ }^{1}$ the authors reported that methyl methacrylate (MMA) was photopolymerized with methyl viologen $\left(\mathrm{MV}^{2+}\right)$ $\mathrm{Na}_{2} \mathrm{~S}_{2} \mathrm{O}_{4}-\mathrm{CCl}_{4}$ as an initiator system in MMA-water two-phase system and that the following cyclic phase-transfer photoinitiation mechanism was suggested for this polymerization. $\mathrm{MV}^{+}$produced by the reduction of $\mathrm{MV}^{2+}$ with $\mathrm{Na}_{2} \mathrm{~S}_{2} \mathrm{O}_{4}$ in the aqueous phase is transferred to the organic phase. $\mathrm{MV}^{+}$ disproportionates to give $1,1^{\prime}$-dimethyl-4,4'bipyridylidene $(\mathrm{MV})$ and $\mathrm{MV}^{2+}$. The fomer reacts with $\mathrm{CCl}_{4}$ photochemically yielding $\mathrm{MV}^{+}$and $\mathrm{CCl}_{3}{ }^{\circ}$ which initiates the polymerization of MMA, and the latter transfers to the aqueous phase. When $N$-benzyl quinolinium chloride was used instead of $\mathrm{MV}^{2+}$ in the initiator system for the polymerization of MMA, $N$-benzyl quinolinium chloride $-\mathrm{Na}_{2} \mathrm{~S}_{2} \mathrm{O}_{4}-\mathrm{CCl}_{4}$ was found to act as an initiator system as $\mathrm{MV}^{2+}-\mathrm{Na}_{2} \mathrm{~S}_{2} \mathrm{O}_{4}-\mathrm{CCl}_{4}$ and polymerize MMA even without photoirra- diation. In this paper, on the basis of kinetic studies an initiation scheme is proposed for the polymerization of MMA with this initiator system in an aqueous-organic system.

\section{EXPERIMENTAL}

\section{Materials}

MMA was purified by usual method just before use. Water was deionized. $\mathrm{BQ}^{+} \mathrm{Cl}^{-}$was prepared by the Menschutkin reaction. All other chemicals used in this study were of reagent grade.

\section{Polymerization}

Polymerization was carried out at a constant stirring rate in a four-necked flask under nitrogen atomosphere at $303 \mathrm{~K}$. In a four-necked round-bottomed $100 \mathrm{~cm}^{3}$ flask equipped with a mechanical stirrer, an inlet-tube of $\mathrm{N}_{2}$, a Dimroth condenser with an outlet-tube of $\mathrm{N}_{2}$, and a dropping funnel were placed 
prescribed amounts of $\mathrm{N}$-benzyl quionolinium chloride, $\mathrm{Na}_{2} \mathrm{~S}_{2} \mathrm{O}_{4}$, and $\mathrm{Na}_{2} \mathrm{CO}_{3}$. After completely dissolved in water degassed under $\mathrm{N}_{2}$, degassed MMA containing $\mathrm{CCl}_{4}$ was added through the dropping funnel. The mixture was stirred at a constant rate for an hour under stream of $\mathrm{N}_{2}$ and the contents were poured into a large amount of aqueous methanol. The precipitated polymer was filtered, washed several times with water and methanol, and dried in vacuo.

\section{RESULTS AND DISCUSSION}

The polymerization of MMA with $\mathrm{BQ}^{+} \mathrm{Cl}^{-}$ $\mathrm{Na}_{2} \mathrm{~S}_{2} \mathrm{O}_{4}-\mathrm{CCl}_{4}$ was carried out in an aqueousorganic two-phase system, where MMA polymerized even at $303 \mathrm{~K}$. When one of these three components was excluded, however, polymerization was remarkably suppressed.

Table I. Polymerization of MMA with $\mathrm{BQ}^{+} \mathrm{Cl}^{--}$ $\mathrm{Na}_{2} \mathrm{~S}_{2} \mathrm{O}_{4}-\mathrm{CCl}_{4}$ in the aqueous-organic, two-phase system ${ }^{\text {a }}$

\begin{tabular}{|c|c|c|c|}
\hline $\mathrm{BQ}^{+} \mathrm{Cl}^{-}$ & $\mathrm{Na}_{2} \mathrm{~S}_{2} \mathrm{O}_{4}$ & $\mathrm{CCl}_{4}$ & Conversion \\
\hline mmol & $\mathrm{mmol}$ & mmol & $\%$ \\
\hline 0.05 & 1 & 5 & 6.82 \\
\hline- & 1 & 5 & 1.75 \\
\hline 0.05 & - & 5 & 0 \\
\hline 0.05 & 1 & - & 0 \\
\hline
\end{tabular}

${ }^{a}$ MMA, $10 \mathrm{~cm}^{3} ; \mathrm{H}_{2} \mathrm{O}, 40 \mathrm{~cm}^{3} ; \mathrm{Na}_{2} \mathrm{CO}_{3}, 7.5 \mathrm{mmol} ;$ temp, $303 \mathrm{~K}$; time, $1 \mathrm{~h}$; stirring, $390 \mathrm{rpm}$.

Table II. Polymerization of MMA with $\mathrm{BQ}^{+} \mathrm{Cl}^{-}$ reductant $-\mathrm{CCl}_{4}$ in the aqueous-organic, two-phase system ${ }^{\text {a }}$

\begin{tabular}{cc}
\hline & \multicolumn{1}{c}{ Conversion } \\
\cline { 2 - 2 } Reductant & $\%$ \\
\hline $\mathrm{Na}_{2} \mathrm{~S}_{2} \mathrm{O}_{4}$ & 6.82 \\
$\mathrm{NaHSO}_{3}$ & 0 \\
$\mathrm{Na}_{2} \mathrm{SO}_{3}$ & 0 \\
\hline
\end{tabular}

a MMA, $10 \mathrm{~cm}^{3} ; \mathrm{H}_{2} \mathrm{O}, 40 \mathrm{~cm}^{3} ; \mathrm{BQ}^{+} \mathrm{Cl}^{-}, 0.5 \mathrm{mmol}$; reductant, $1 \mathrm{mmol} ; \mathrm{CCl}_{4}, 5 \mathrm{mmol} ; \mathrm{NaCO}_{3}, 7.5 \mathrm{mmol}$; temp, $303 \mathrm{~K}$; time, $1 \mathrm{~h}$; stirring speed, $390 \mathrm{rpm}$.
No polymerization was induced at all without either $\mathrm{Na}_{2} \mathrm{~S}_{2} \mathrm{O}_{4}$ or $\mathrm{CCl}_{4}$ (Table I). This shows that these three components form one initiator system for the polymerization of MMA. When $\mathrm{NaHSO}_{3}$ or $\mathrm{Na}_{2} \mathrm{SO}_{3}$ was used in place of $\mathrm{Na}_{2} \mathrm{~S}_{2} \mathrm{O}_{4}$, no polymerization occurred (Table II).

Little is known about the reactions of quinolinium salts with dithionites and unsuccessful attempts were made to characterize the products from the reaction of 1-substituted quinolinium salts with sodium dithionite. ${ }^{2}$ However, the mechanism of reduction of pyridinium salts with dithionite has been elucidated to proceed via an intermediate sodium sulfinate, which is stable in alkaline solution and has been isolated. ${ }^{3}$ Inoue et al., reported the dehalogenation reaction by sodium 1benzyl-1,4-dihydronicotinamide-4-sulfinate which was isolated in the course of the reduction of 1-benzylnicotiamide with $\mathrm{Na}_{2} \mathrm{~S}_{2} \mathrm{O}_{4}$ as an intermediate, and they also reported the usefulness of the sulfinate as a reducing agent. ${ }^{4}$

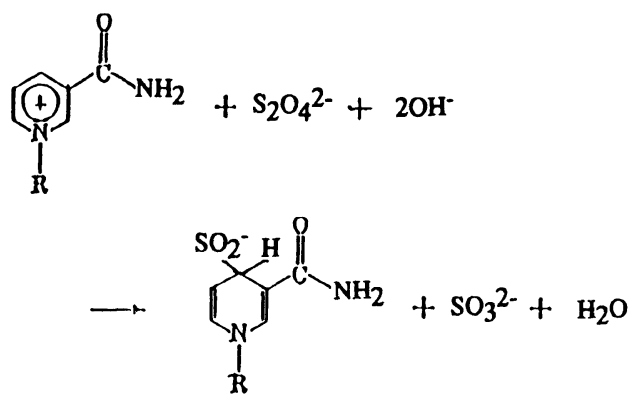

The polymerization of MMA was carried out in the aqueous-organic two-phase system with changing feed ratios of $\mathrm{BQ}^{+} \mathrm{Cl}^{-}, \mathrm{Na}_{2} \mathrm{~S}_{2} \mathrm{O}_{4}$, and $\mathrm{CCl}_{4}$, and the conversions of MMA were plotted against time. Conversion-time relationships for varying $\mathrm{BQ}^{+} \mathrm{Cl}^{-}$concentrations are shown in Figure 1. The polymerizations proceeded fast at the beginning, but became gradually slow with reaction time. This suggests that the reaction of $\mathrm{BQ}^{+} \mathrm{Cl}^{-}$with $\mathrm{Na}_{2} \mathrm{~S}_{2} \mathrm{O}_{4}$ is more complicated than that of pyridinium salts with $\mathrm{Na}_{2} \mathrm{~S}_{2} \mathrm{O}_{4}$, and some other reaction products which do not take part in the 


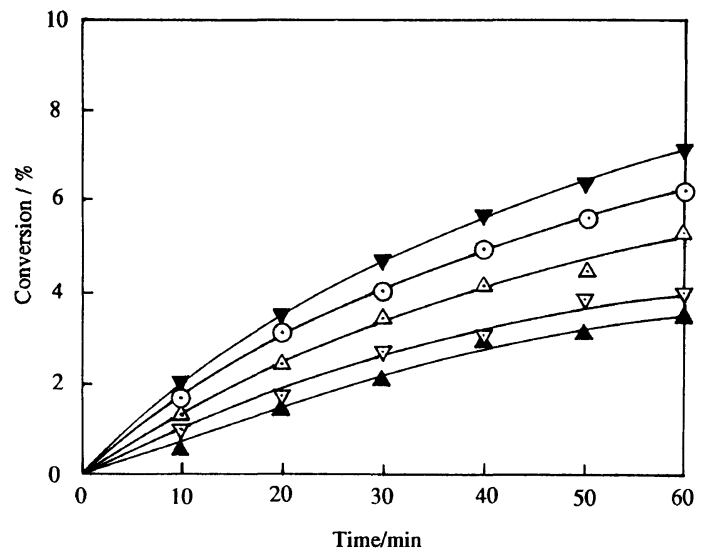

Figure 1. Polymerization of $\mathrm{MMA}$ with $\mathrm{BQ}^{+} \mathrm{Cl}^{-}$ $\mathrm{Na}_{2} \mathrm{~S}_{2} \mathrm{O}_{4}-\mathrm{CCl}_{4}$ in aqueous organic, two-phase system: MMA, $10 \mathrm{~cm}^{3} ; \mathrm{H}_{2} \mathrm{O}, 40 \mathrm{~cm}^{3} ; \mathrm{BQ}^{+} \mathrm{Cl}^{-}, 0.005 \mathrm{mmol}$ $(\mathbf{\Delta}), 0.01 \mathrm{mmol}(\nabla), 0.03 \mathrm{mmol}(\triangle), 0.05 \mathrm{mmol}(\odot), 0.1$ $\mathrm{mmol}(\boldsymbol{\nabla}) ; \mathrm{Na}_{2} \mathrm{~S}_{2} \mathrm{O}_{4}, 1 \mathrm{mmol} ; \mathrm{CCl}_{4}, 5 \mathrm{mmol} ; \mathrm{Na}_{2} \mathrm{CO}_{3}$, $7.5 \mathrm{mmol}$; temp, $303 \mathrm{~K}$; stirring rate, $390 \mathrm{rpm}$.

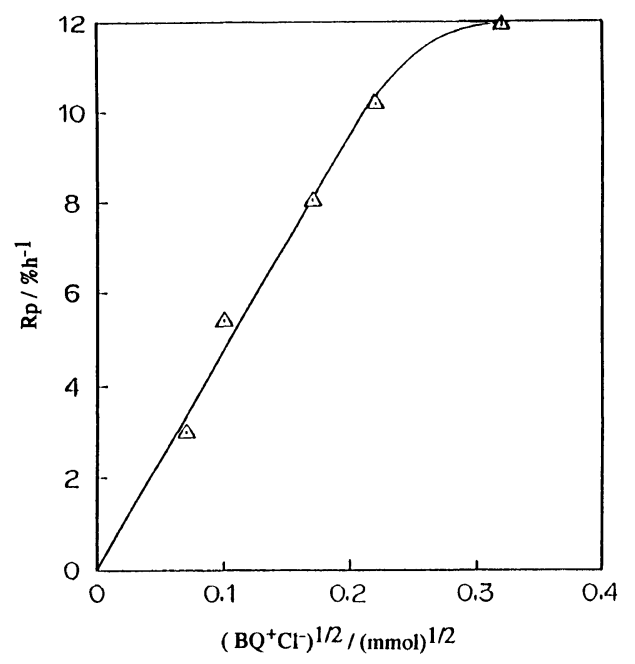

Figure 2. Relation of $R_{\mathrm{p}} v s$. $\left(\mathrm{BQ}^{+} \mathrm{Cl}^{-}\right)^{1 / 2}$ for polymerization of MMA with $\mathrm{BQ}^{+} \mathrm{Cl}^{-}-\mathrm{Na}_{2} \mathrm{~S}_{2} \mathrm{O}_{4}-\mathrm{CCl}_{4}$ in aqueous organic, two-phase system: MMA, $10 \mathrm{~cm}^{3} ; \mathrm{H}_{2} \mathrm{O}, 40 \mathrm{~cm}^{3}$; $\mathrm{Na}_{2} \mathrm{~S}_{2} \mathrm{O}_{4}, 1 \mathrm{mmol} ; \mathrm{CCl}_{4}, 5 \mathrm{mmol} ; \mathrm{Na}_{2} \mathrm{CO}_{3}, 7.5 \mathrm{mmol}$; temp, $303 \mathrm{~K}$; stirring speed, $390 \mathrm{rpm}$.

polymerization are produced besides sodium $\mathrm{N}$-benzyl-1,4-dihydro-qunoline-4-sulfinate (BQ-sulfinate) which is expected as the main product from analogy of the reaction of pyridinium salts with $\mathrm{Na}_{2} \mathrm{~S}_{2} \mathrm{O}_{4}$.

The initial rate of polymerization $\left(R_{\mathrm{p}}\right)$ was

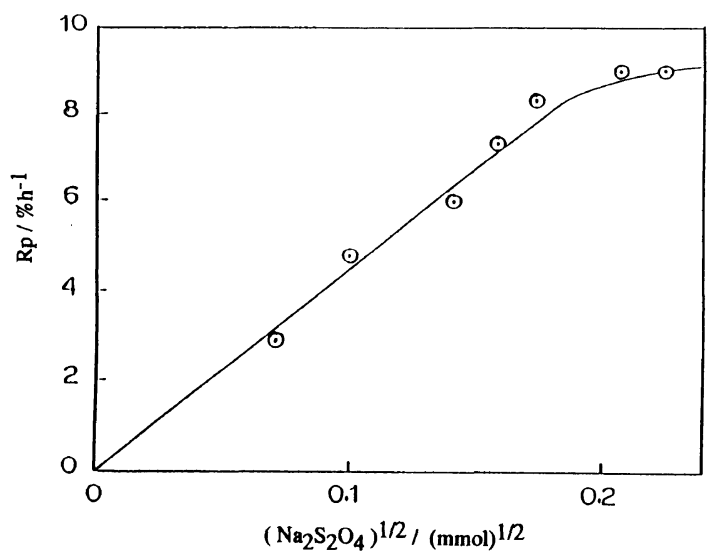

Figure 3. Relation of $R_{\mathrm{p}} v s .\left(\mathrm{N}_{2} \mathrm{~S}_{2} \mathrm{O}_{4}\right)^{1 / 2}$ for polymerization of MMA with $\mathrm{BQ}^{+} \mathrm{Cl}^{-}-\mathrm{Na}_{2} \mathrm{~S}_{2} \mathrm{O}_{4}-\mathrm{CCl}_{4}$ in aqueous organic, two-phase system: MMA, $10 \mathrm{~cm}^{3} ; \mathrm{H}_{2} \mathrm{O}, 40 \mathrm{~cm}^{3}$; $\mathrm{BQ}^{+} \mathrm{Cl}^{-}, 0.05 \mathrm{mmol} ; \mathrm{CCl}_{4}, 5 \mathrm{mmol} ; \mathrm{Na}_{2} \mathrm{CO}_{3}, 7.5 \mathrm{mmol}$; temp, $303 \mathrm{~K}$; stirring speed, $390 \mathrm{rpm}$.

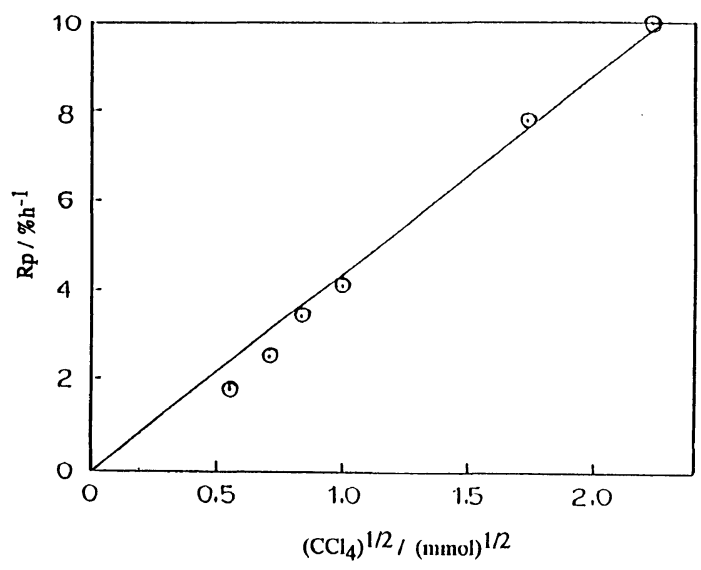

Figure 4. Relation of $R_{\mathrm{p}} v s .\left(\mathrm{CCl}_{4}\right)^{1 / 2}$ for polymerization of MMA with $\mathrm{BQ}^{+} \mathrm{Cl}^{-}-\mathrm{Na}_{2} \mathrm{~S}_{2} \mathrm{O}_{4}-\mathrm{CCl}_{4}$ in aqueous organic, two-phase system: MMA, $10 \mathrm{~cm}^{3} ; \mathrm{H}_{2} \mathrm{O}, 40 \mathrm{~cm}^{3}$; $\mathrm{BQ}^{+} \mathrm{Cl}^{-}, 0.05 \mathrm{mmol} ; \mathrm{Na}_{2} \mathrm{~S}_{2} \mathrm{O}_{4}, 1 \mathrm{mmol} ; \mathrm{Na}_{2} \mathrm{CO}_{3}, 7.5$ $\mathrm{mmol}$; temp, $303 \mathrm{~K}$; stirring speed, $390 \mathrm{rpm}$.

plotted against the square root of fed quantity of $\mathrm{BQ}^{+} \mathrm{Cl}^{-}$and a linear relationship was observed as shown in Figure 2. The downward drift at a higher concentration of $\mathrm{BQ}^{+} \mathrm{Cl}^{-}$can be explained by the following. White crystalline product, possibly $\mathrm{BQ}$-sulfinate, precipitates from the reaction system at a high concentration before adding MMA, so that the concentration of BQ-sulfinate in the aqueous 


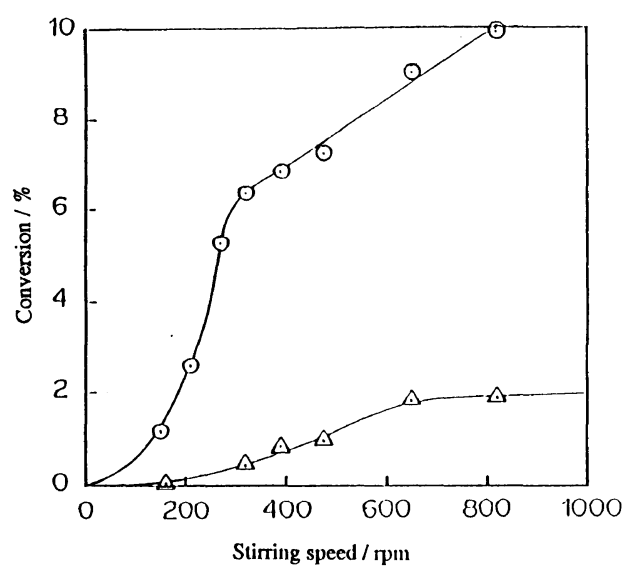

Figure 5. Relation of Conv. vs. stirring speed for polymerization of MMA with $\mathrm{BQ}^{+} \mathrm{Cl}^{-}-\mathrm{Na}_{2} \mathrm{~S}_{2} \mathrm{O}_{4}-\mathrm{CCl}_{4}$ in aqueous organic, two-phase system: MMA, $10 \mathrm{~cm}^{3} ; \mathrm{H}_{2} \mathrm{O}$, $40 \mathrm{~cm}^{3} ; \mathrm{BQ}^{+} \mathrm{Cl}^{-}, 0.05 \mathrm{mmol}(\odot)$, none $(\triangle) ; \mathrm{Na}_{2} \mathrm{~S}_{2} \mathrm{O}_{4}$, $1 \mathrm{mmol} ; \mathrm{CCl}_{4}, 5 \mathrm{mmol} ; \mathrm{Na}_{2} \mathrm{CO}_{3}, 7.5 \mathrm{mmol}$; temp, $303 \mathrm{~K}$; time, $1 \mathrm{~h}$.

phase does not increase over its solubility. BQ-Sulfinate, however, could not be isolated due to its unstability. The initial rates of polymerization were plotted against the square root of fed quantity of the other initator components, $\mathrm{Na}_{2} \mathrm{~S}_{2} \mathrm{O}_{4}$, and $\mathrm{CCl}_{4}$. Linear relationships were also observed between them (Figures 3 and 4).

In the presence of an excess of $\mathrm{Na}_{2} \mathrm{~S}_{2} \mathrm{O}_{4}$, however, $R_{\mathrm{p}}$ gradually decreased and became constant. Figure 3 shows that $R_{\mathrm{p}}$ is proportional to the square root of the fed quantity of $\mathrm{Na}_{2} \mathrm{~S}_{2} \mathrm{O}_{4}$ when the concentration of $\mathrm{Na}_{2} \mathrm{~S}_{2} \mathrm{O}_{4}$ is less than equivalent of $\mathrm{BQ}^{+} \mathrm{Cl}^{-}$. These results suggest that the reaction between $\mathrm{BQ}^{+} \mathrm{Cl}^{-}$and $\mathrm{Na}_{2} \mathrm{~S}_{2} \mathrm{O}_{4}$ in aqueous phase is very fast.

The rate of polymerization in the aqueousorganic two phase was also affected by the rate of stirring as shown in Figure 5. Particularly around $200-300 \mathrm{rpm}$ the conversion rapidly increased with stirring rate. This may be due to the remarkable increase in the intersurface area between the two phases with an increase in stirring speed, which facilitates the phase transfer of BQ-sulfinate. These results suggest the initiation mechanism shown in Figure 6.

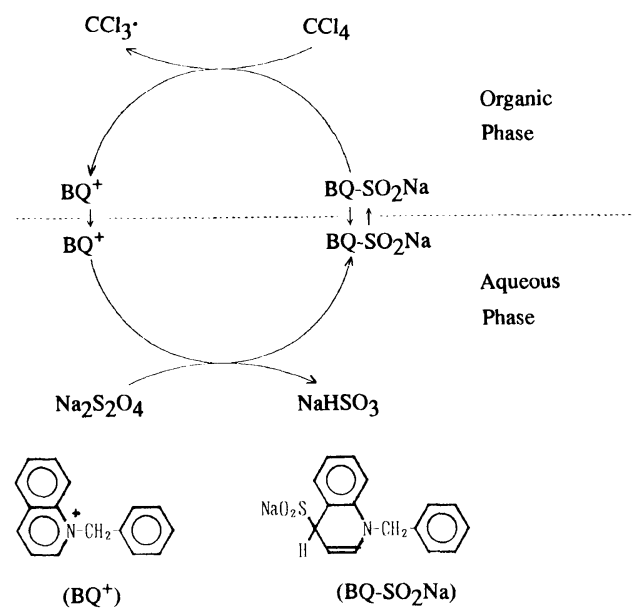

Figure 6. Scheme for the polymerization of MMA with $\mathrm{BQ}^{+} \mathrm{Cl}^{-}-\mathrm{Na}_{2} \mathrm{~S}_{2} \mathrm{O}_{4}-\mathrm{CCl}_{4}$ in the aqueous-organic, two phase system.

$\mathrm{BQ}^{+} \mathrm{Cl}^{-}$in the aqueous phase was reduced by $\mathrm{Na}_{2} \mathrm{~S}_{2} \mathrm{O}_{4}$ into sodium $N$-benzyl-1,4-dihydroquinoline-4-sulfinate (BQ-sulfinate), which is transferred to the organic phase from the aqueous phase by vigorous stirring. BQsulfinate in the organic phase reacts with $\mathrm{CCl}_{4}$ to yield $\mathrm{BQ}^{+}$and $\mathrm{CCl}_{3} \cdot$. The former is recycled to the aqueous phase and the latter initiates the polymerization of MMA.

Acknowledgements. The authors are grateful to Dr. N. Sakota, Sakota Chemical Developement and Research Institute Co., Ltd., for his valuable comments and helpful advices.

\section{REFERENCES}

1. S. Shimada, Y. Obata, K. Nakagawa, and K. Tabuchi, Polym. J., 22, 777 (1990).

2. P. Karrer, F. W. Kahnt, R. Epstein, W. Jaffe, and T. Ishii, Helv. Chim. Acta, 21, 223 (1938).

3. W. S. Caughey and K. A. Schellenberg, J.Org. Chem., 31, 1908 (1966); J. F. Biellmann and H. J. Callot, Bull. Soc. Chim. Fr., 1154 (1968); J. F. Biellmann and H. J. Callot, ibid., 1299 (1969).

4. H. Inoue, N. Inoguchi, and E. Imoto, Bull. Chem. Soc. Jpn., 50, 197 (1977). 